\title{
BUCKLING RESISTANCE OF AXIALLY RESTRAINED CHORD MEMBER OF GRID STRUCTURE AT ELEVATED TEMPERATURE
}

\author{
Du Yong ${ }^{\mathrm{a}, \mathrm{b}}$, J.Y. Richard Liew ${ }^{\mathrm{a}, \mathrm{b}}$, Mingxiang Xiong $^{\mathrm{b}}$, Jie Zou $^{\mathrm{a}}, \mathrm{Zeng} \mathrm{Bo}^{\mathrm{c}}$ \\ ${ }^{a}$ Nanjing Tech University, College of Civil Engineering, Jiangsu, China \\ ${ }^{\mathrm{b}}$ National University of Singapore, Department of Civil \& Environmental Engineering, Singapore \\ ${ }^{c}$ Architectual Design and Research Institute of Nanjing Tech University
}

\begin{abstract}
This paper investigates the behavior of large span grid structure exposed to a localized fire. The localized fire may generate hot smoke and thus induce non-uniform temperature distribution in the grid structure. The thermal expansion of the heated members tend to be axially restrained by the adjacent cold members thus inducing additional forces on the critical members of the grid structure. The buckling resistance of axially restrained member at elevated temperature may be obtained based on second order analysis of member with initial lateral imperfection by considering force equilibrium at deformed geometry and cross section resistance being reached. The critical temperature of the member is reached when the axial force reaches its buckling resistance. It is found that the critical temperature of members with initial lateral imperfection was higher than that without such imperfection for chord members with large slenderness ratio and high axial restraint.
\end{abstract}

Keywords:axially restrained chord member, buckling temperature, initial lateral imperfection

\section{INTRODUCTION}

Spatial grid structures are extensively employed by buildings with long span roof, which would be subjected to localized fires. Since the temperature distributions throughout the localized fire are non-uniform, the longatinal thermal expansion of hotter chord members may be restrained by the less hotter chord members, and occur thermal stress in the hotter (e.g. Du Y. et al.,2014).In gerenal, the restraint would reduce the buckling resistance.Then, behaviours of restrained members of steel frames at elevated temperature are deeply analized(e.g. I. C. Neveset al.,1983, J. M. Franssen. 2000, Wang P. Jet al.,2009). Is there any difference between frame members and chord members? It is distinct that chord members are always with larger slender ratio than frame members, especially for tension chord members which shall be inversed to the compression at elevated temperature (e.g. Du Y. et al.,2014). It must be deeplydiscovered thatthe intial lateral imperfection acts on the buckling capacity and the axially restrained member with muchhigher slender ratioresponds under elevated temperature.

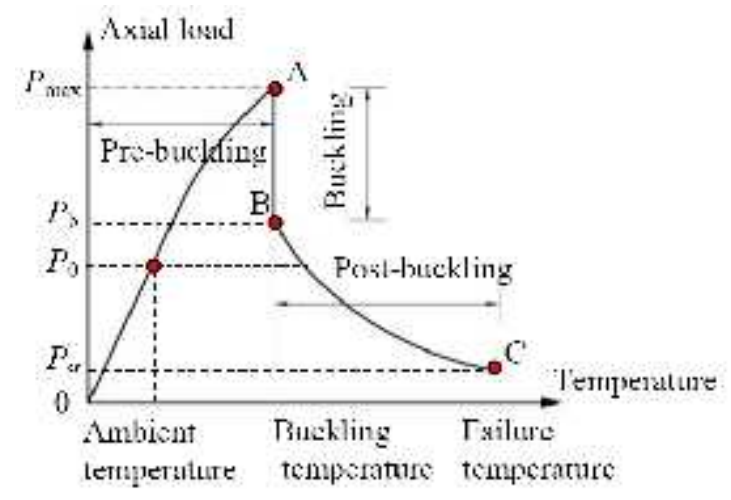

Fig. 1 Axial load-temperaturecurvefor an axially restrained members

Shown as Fig.1the buckling temperature at point $\mathrm{A}$ is dependent on the pre-buckling history strongly. If the point A is pushed forwards by pre-buckling history, the post-buckling history will be 
revised. Therefore, pre-buckling behaviors of the axially restrained chord members with initial lateral imperfections and large slender ratio under elevated temperature must be distinct as following.

\section{AXIAL BEHAVIOR OFEND-RESTRAINED CHORD MEMBERS WITH INITIAL LATERAL IMPERFECT}

The proceeding of deformation for a axially restrained chord member with lateral initial imperfection is shown as Fig. 2graphically.

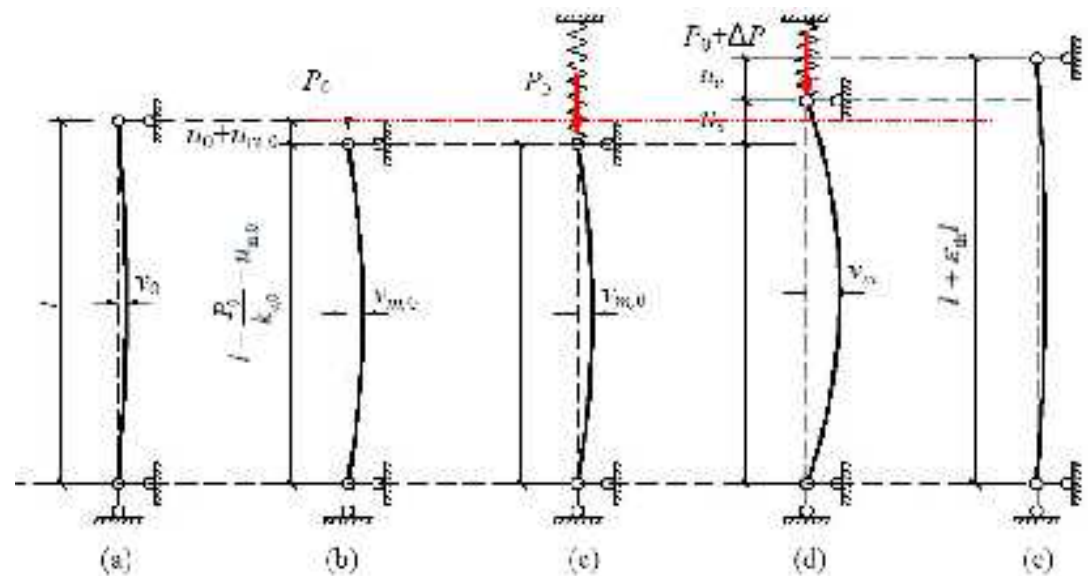

Fig.2 Deformation for a chord member with initial imperfection at ambient temperature and elevated temperatures

Figure 2(a) shows a simply supported chord member with an initial bow imperfectionwith maximum magnitude $v_{0}$ at the mid-height. The vertical displacement $u_{0}$, caused by axial load $P_{0}$, is superimposed by $u_{\mathrm{m}, 0}$ caused by thecurvature effect due to bending at ambient temperature. When the chord member is further exposed to fire, the restraint effect due to adjacent structure can be Meanwhile, the axial load causes a lateral deformation, $v_{\mathrm{m}, 0}$ at the mid-height as shown in Fig.2(b). When the chord member is further exposed to fire, the restraint effect due to adjacent structure can be represented by a restraining spring attached at one end, as shown in Fig. 2(c).As shown in Figure 2(d), an upward displacement of us due to thermal expansion is observed, and a downward displacement of uc due to initial force and the additional restrained force, $P+P$ upon the freedom thermal expansion chord member, as shown in Fig. 2(e).

\section{MECHANICAL RESPONSE OF AXIALLY RESTRAINED CHORD MEMBERS WITH INITIAL LATERAL IMPERFECTION}

At ambient temperature, the total vertical deformation, $u^{\prime}$, as following

$$
u^{\prime}=u_{\mathrm{D}}+u_{\mathrm{LI}, \mathrm{D}}=\frac{P_{\mathrm{U}}}{\kappa_{\mathrm{L}, \mathrm{U}}}+u_{\mathrm{LI}, \mathrm{D}}
$$

where $k_{\mathrm{L}, 0} \quad$ the axial stiffness of a chord member at ambient temperature.

At elevated temperature, the longitudinal thermal expansion, $u_{\mathrm{s}}$, of a chord member is under the spring with restrained stiffness, $k_{\mathrm{s}}$ and initial force $P_{0}$. Then, the loading, $\Delta P$, caused by spring can be given as

andthe total loading, $P_{\mathrm{T}}$, is given as $E q$. (3) considering of $E q$. (2)

$$
\Delta P=k_{\mathrm{s}} u_{\mathrm{s}}(2)
$$

$$
P_{\mathrm{T}}=P_{0}+\Delta P=P_{0}+k_{\mathrm{s}} u_{\mathrm{s}}(3)
$$

longitudinal thermal expansion, $\Delta l$, in Fig.3(e) is given as

where $\alpha_{\mathrm{T}} \quad$ thermal expansion coefficient, $\left[1.4 \times 10^{-5} /{ }^{\circ} \mathrm{C}\right]$,

$$
\Delta l=\alpha_{\mathrm{T}} l(\Delta T)=\varepsilon_{\mathrm{th}} l(4)
$$

$\Delta \mathrm{T} \quad$ step of temperatureincrement. 
Ifloading $P_{\mathrm{T}}$ on the freedom chord member, see Fig. 3(e), the longitudinal deformation is represent by $u_{\mathrm{c}}$, which combines with axially loading action and lateral bending action. The deformation caused by axially loading action can be given as

$$
u_{\mathrm{c}}-u_{\mathrm{m}}=\left(P_{0}+\Delta P\right) / k_{\mathrm{c}}(5)
$$

where, $u_{\mathrm{m}} \quad$ the longitudinal deformation caused by lateral bending at elevated temperature,

$k_{\mathrm{c}} \quad$ axial stiffness of a chord member at elevated temperature.

substitutingEq. (2) into Eq. (5), then

$$
u_{\mathrm{c}}-u_{\mathrm{m}}=\left(P_{0}+k_{s} u_{s}\right) / k_{\mathrm{c}}(6)
$$

let Fig. 3(d) compare with Fig. 3(b) and Fig. 3(e), there is a relationship of deformation as below

substitutingEq.(6)into Eq.(7), then

$$
u_{s}+u_{c}=\varepsilon_{\mathrm{th}} l+\frac{P_{0}}{k_{\mathrm{c}, 0}}+u_{\mathrm{m}, 0}(7)
$$

$$
u_{s}=\frac{k_{\mathrm{c}}}{k_{\mathrm{s}}+k_{\mathrm{c}}}\left(\varepsilon_{\mathrm{th}} l-\frac{p_{0}}{k_{c}}+\frac{p_{0}}{k_{c, 0}}+u_{m, 0}-u_{\mathrm{m}}\right)
$$

let $u_{\text {mec }}=\frac{p_{0}}{k_{c, 0}}-\frac{p_{0}}{k_{c}}$, then

substitutingEq. (9) into $E q$. (3), then

$$
u_{s}=\frac{k_{\mathrm{c}}}{k_{\mathrm{s}}+k_{\mathrm{c}}}\left(\varepsilon_{\mathrm{th}} l-u_{\mathrm{mec}}+u_{\mathrm{m}, 0}-u_{\mathrm{m}}\right)
$$

$$
P_{\mathrm{T}}=P_{0}+\frac{k_{\mathrm{s}} k_{\mathrm{c}}}{k_{\mathrm{s}}+k_{\mathrm{c}}}\left(\varepsilon_{\mathrm{th}} l-u_{\mathrm{mec}}+u_{\mathrm{m}, 0}-u_{\mathrm{m}}\right)
$$

in order to consider of the effect of initial lateral imperfect, $v_{0}$, for longitudinal deformation, the relationship between initial lateral imperfect and longitudinal deformation should be established as below. Shown as Fig.3, based on the mechanical modelof second order analysis for the chord member with lateral initial imperfection, the function of displacement for chord membersis illustrated as following.

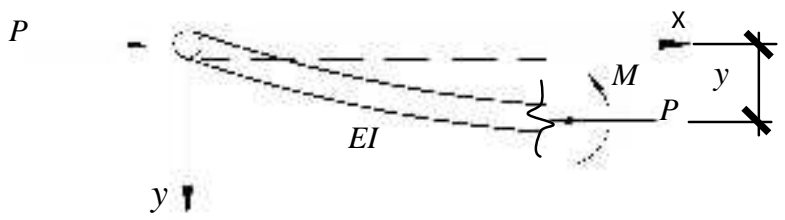

Fig. 3 Analysis model of deflection curve for steel members

The function of lateraldisplacement for initial lateral imperfect is given by Eq.(11)

where $l \quad$ initiallength of a chord member,

$$
y_{0}=v_{0} \sin \frac{\pi x}{l}
$$

$v_{0} \quad$ initiallateral imperfection, $v_{0}=l / 1000$.

The force differential equation of the lateral displacement is given by Eq.(12).

where EI flexural rigidity of a chord member at ambient temperature.

let $\frac{P}{E I}=k^{2}$ and substituting Eq.(11) into Eq. (12), as following 


$$
y^{\prime \prime}+k^{2} y=-\frac{v_{0} \pi^{2}}{l^{2}} \sin \left(\frac{\pi x}{l}\right)
$$

the general solution of partial differential Eq. (13)as below

$$
y=A \sin (k x)+B \cos (k x)-\frac{\pi^{2} v_{0}}{k^{2} l^{2}-\pi^{2}} \sin \left(\frac{\pi x}{l}\right)
$$

where $A, B$ undetermined coefficients.

inducing boundary conditions to $E q$. (14), i.e.if $x=0$ or $x=l$, then $y=0$, the function of lateral deflection equation with initial lateral imperfect can be obtained

$$
y=-\frac{\pi^{2} v_{0}}{k^{2} l^{2}-\pi^{2}} \sin \left(\frac{\pi x}{l}\right)
$$

Then, the longitudinal displacements of a axially restrained chord membercaused by bending action at ambient temperature and elevated temperature as following

$$
\begin{aligned}
& u_{\mathrm{m}, 0}=\frac{1}{2} \int_{0}^{l} y^{\prime 2}\left(P_{0}\right) \mathrm{d} x(16) \\
& u_{\mathrm{m}}=\frac{1}{2} \int_{0}^{l} y^{\prime 2}\left(P_{\mathrm{T}}\right) \mathrm{d} x(17)
\end{aligned}
$$

substitutingEq. (16)and Eq. (17)into Eq. (10), then

$$
P_{0}+\frac{k_{\mathrm{s}} k_{\mathrm{c}}}{k_{\mathrm{s}}+k_{\mathrm{c}}}\left[\varepsilon_{\mathrm{th}} l-u_{\mathrm{mec}}+\frac{1}{2} \int_{0}^{l} y^{\prime 2}\left(P_{0}\right) \mathrm{d} x-\frac{1}{2} \int_{0}^{l} y^{\prime 2}\left(P_{\mathrm{T}}\right) \mathrm{d} x\right]-P_{\mathrm{T}}=0
$$

integralEq. (18), then

$$
P_{0}+\frac{k_{\mathrm{s}} k_{\mathrm{c}}}{k_{\mathrm{s}}+k_{\mathrm{c}}}\left\{\varepsilon_{\mathrm{th}} l-u_{\mathrm{mec}}+\frac{I^{2} \pi^{6} v_{0}^{2}}{4 l}\left[\left(\frac{E_{0}}{P_{0} l^{2}-E_{0} l \pi^{2}}\right)^{2}-\left(\frac{E_{\mathrm{T}}}{P_{\mathrm{T}} l^{2}-E_{\mathrm{T}} I \pi^{2}}\right)^{2}\right]\right\}-P_{\mathrm{T}}=0
$$

the transient axial force of chord members can be gotten by solving Eq. (19) at any temperature point with MATLAB calculation software.

\section{INITIAL LATERAL IMPERFECTIONACTION ON BUCKLING RESISTANCE}

Reference of $E q$. (10), the axial force of achord member without initial lateral imperfection can be given as below

$$
P_{\mathrm{T}}^{\prime}=P_{0}+\frac{k_{\mathrm{s}} k_{\mathrm{c}}}{k_{\mathrm{s}}+k_{\mathrm{c}}}\left(\varepsilon_{\mathrm{th}} l-u_{\mathrm{mec}}\right)
$$

letEq. (20)minusEq. (10), then the initial lateral imperfect action, $P_{\mathrm{b}}$, is given as below

$$
P_{\mathrm{b}}=P_{\mathrm{T}}^{\prime}-P_{\mathrm{T}}=\frac{k_{\mathrm{s}} k_{\mathrm{c}}}{k_{\mathrm{s}}+k_{\mathrm{c}}}\left(u_{\mathrm{m}}-u_{\mathrm{m}, 0}\right)
$$

givenrestraint ratio $\beta_{1}=k_{\mathrm{s}} / k_{\mathrm{c}}$, then

$$
P_{\mathrm{b}}=k_{\mathrm{c}}\left(1-\frac{1}{1+\beta_{1}}\right)\left(u_{\mathrm{m}}-u_{\mathrm{m}, 0}\right)
$$

at ambient temperature, let $\frac{P_{0}}{E I}=k_{0}{ }^{2}$ and substituting Eq. (15)into Eq. (16), then

$$
\begin{aligned}
u_{\mathrm{m}, 0} & =\frac{1}{2}\left(\frac{\pi^{2} v_{0}}{k_{0}{ }^{2} l^{2}-\pi^{2}}\right)^{2} \int_{0}^{l}\left(\frac{\pi}{l}\right)^{2} \cos ^{2}\left(\frac{\pi x}{l}\right) \mathrm{d} x \\
& =\frac{1}{4 l}\left(\frac{\pi^{3} v_{0}}{k_{0}{ }^{2} l^{2}-\pi^{2}}\right)^{2} \\
& =\frac{l}{4}\left(\frac{\pi^{3}}{\pi^{2}-k_{0}{ }^{2} l^{2}}\right)^{2} \times 10^{-6}
\end{aligned}
$$


at elevated temperature, let $\frac{P_{\mathrm{T}}}{E_{\mathrm{T}} I}=k_{\mathrm{T}}{ }^{2}$ and substituting Eq. (15)into Eq. (17), similar to Eq. (23)as below

$$
u_{\mathrm{m}}=\frac{l}{4}\left(\frac{\pi^{3}}{\pi^{2}-k_{\mathrm{T}}^{2} l^{2}}\right)^{2} \times 10^{-6}
$$

because $k_{0}, v_{0}$ and $l$ should be given for a chord member at ambient temperature, the value of axial deformation, $u_{\mathrm{m}, 0}$, caused by bending can be gotten fromEq. (23). Then, According to Eq. (22), the initial lateral imperfect action, $P_{\mathrm{b}}$, is mainly dependent on $u_{\mathrm{m}}$ and $k_{\mathrm{c}}\left(1-\frac{1}{1+\beta_{1}}\right)$.

According to $E q$. (24), the factor, $k_{\mathrm{T}}{ }^{2}$, should be noted firstly. Then,calculating $P_{\mathrm{T}}$ withEq. (19), the history of $k_{\mathrm{T}}{ }^{2}$ atelevated temperature is shown as Fig. 4, which is for a chord member with a given slender ratio, $l / \sqrt{I / A}=200$.

Let

where $P_{\mathrm{blk}} \quad$ buckling resistance force at fire limit state,

$f_{\mathrm{yT}} \quad$ yield strength at elevated temperature,

A size of section for chord member.

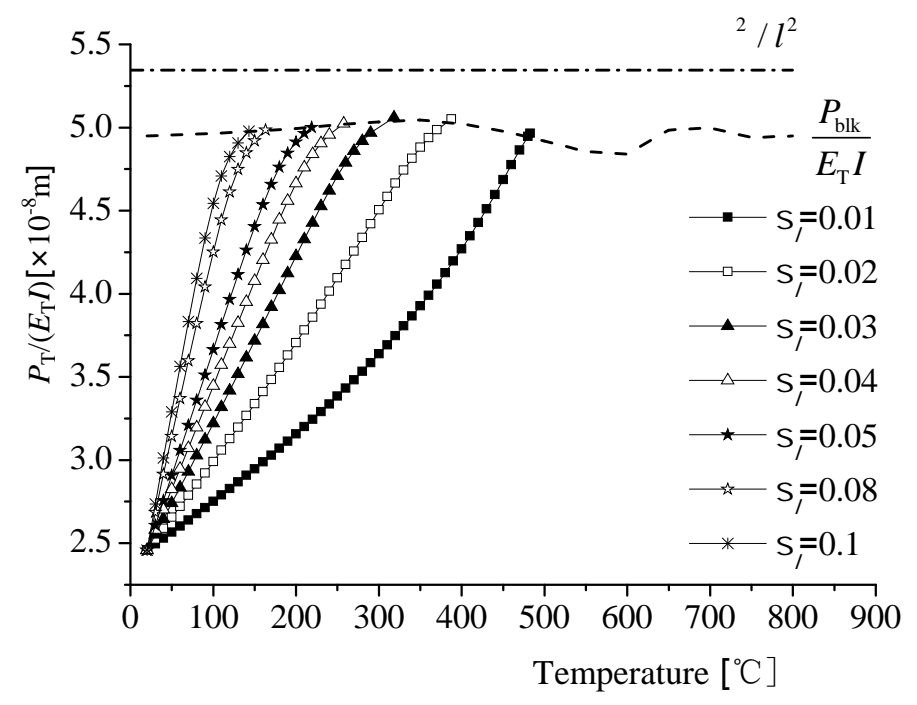

Fig. 4 Thehistory of $\boldsymbol{P}_{\mathrm{T}} /\left(\boldsymbol{E}_{\mathrm{T}} \boldsymbol{I}\right)$ at elevated temperature varied with restrained stiffness ratio

Fig. 4illustrates graphically that $k_{\mathrm{T}}{ }^{2}$ is always below $\pi^{2} / l^{2}$. Then, the $k_{\mathrm{T}}^{2}$ increases with elevated temperature pre-buckling.See $E q$. (24), the term of $\pi^{2}-k_{\mathrm{T}}{ }^{2}{ }^{2}$ reduces with $k_{\mathrm{T}}$ increasing, while $u_{\mathrm{m}}$ increases. According to $E q$. (22), for given $u_{\mathrm{m}, 0}$, the $P_{\mathrm{b}}$ increases at elevated temperature under any restrained ratio.

In the meantime, with the $\beta_{1}$ increasing, the $k_{\mathrm{T}}^{2}$ increases more rapidly, while $u_{\mathrm{m}}$ increases more rapidly also, shown as Fig. 4. Finally, the initial lateral imperfect influences on the axial loading of chord members more strongly with the higher restrained ratio.

Shown as Fig. 5, there is a chord member with slender ration 200 and loading ratio 0.5. in case 1, the axially restrained chord member without initial lateral imperfect and axial loading can be gotten by $E q$. (22), in case 2,the axially restrained chord member with initial lateral imperfect and axial loading can be gotten by Eq. (19). Under higher axially restrained stiffness ratio there is a remarkable distinction of buckling temperature between case 1 and case 2 . 


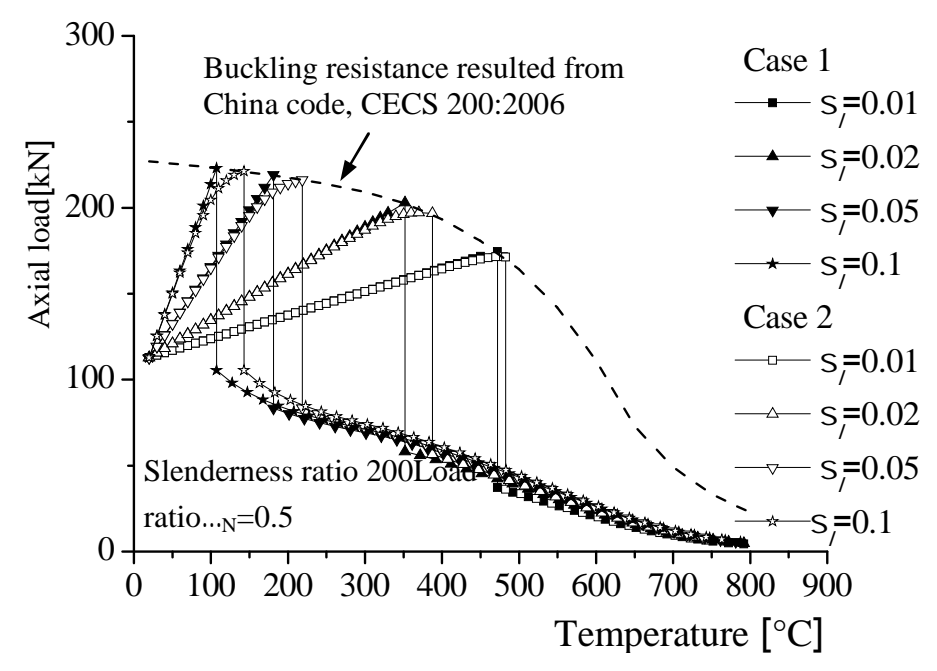

Fig. 5Initial axial imperfect action on the buckling resistance for a chord memberat elevated temperature varied with restrained stiffness ratio

It can be concluded that the initial lateral imperfect provides larger lateral displacement at elevated temperature, in a way, released thermal loading for chord members. However, it postpones the buckling temperature for the chord member with higher restrained stiffness ratio. Therefore, the initial lateral imperfect should be noted enough when evaluating the bulking resistance at elevated temperature for chord members with higher restrained stiffness ratio.

\section{CONCLUSIONS}

The main conclusions of the work presented as following

- Based on the second order analysis of members with initial lateral imperfection, the calculation method of transient axial loading for axially restrained chord members at elevated temperature has been derived.

- The initial lateral imperfection improves the buckling resistance of chord member with higher restrained stiffness ratio.

\section{ACKNOWLEDGMENTS}

This study is apart of the project, whichis supported by National Natural Science Foundation of China.

\section{REFERENCE}

Du Y., Li X., Gu J., 2014. Fire-resistance of Regular Pyramidia Gird Structures Exposed to Localized Fire with New Temperature-time Curve, in 8th international conference on structure in fire, 11-13 June 2014, Shanghai, China, p. 935-942

I. C. Neves. 1983. The Column-structure Interaction on the Behavior of Steel Columns under Local Fire.PhD thesis, The Instituto Superior T'ecnico.

J. M. Franssen. 2000. Failure Temperature of a System Comprising a Restrained ColumnSubmitted to Fire. Fire Safety Journal, 34(2), p.191-207

Wang P. J., Li G. Q., Wang Y.C.2009. Parametric Studies on Restrained SteelColumnin Fire :Under Axial Load Only. Journal of Tongji University: Natural Science , 37(12),p.1571-1575. 
